\title{
Molecular checkpoints controlling natural killer cell activation and their modulation for cancer immunotherapy
}

\author{
Hyung-Joon Kwon ${ }^{1,2}$, Nayoung $\mathrm{Kim}^{3,4}$ and Hun Sik Kim ${ }^{1,2}$
}

Natural killer (NK) cells have gained considerable attention as promising therapeutic tools for cancer therapy due to their innate selectivity against cancer cells over normal healthy cells. With an array of receptors evolved to sense cellular alterations, NK cells provide early protection against cancer cells by producing cytokines and chemokines and exerting direct cytolytic activity. These effector functions are governed by signals transmitted through multiple receptor-ligand interactions but are not achieved by engaging a single activating receptor on resting NK cells. Rather, they require the co-engagement of different activating receptors that use distinct signaling modules, due to a cell-intrinsic inhibition mechanism. The redundancy of synergizing receptors and the inhibition of NK cell function by a single class of inhibitory receptor suggest the presence of common checkpoints to control NK cell activation through different receptors. These molecular checkpoints would be therapeutically targeted to harness the power of NK cells against diverse cancer cells that express heterogeneous ligands for NK cell receptors. Recent advances in understanding the activation of NK cells have revealed promising candidates in this category. Targeting such molecular checkpoints will facilitate NK cell activation by lowering activation thresholds, thereby providing therapeutic strategies that optimize NK cell reactivity against cancer.

Experimental \& Molecular Medicine (2017) 49, e311; doi:10.1038/emm.2017.42; published online 31 March 2017

\section{INTRODUCTION}

Since the discovery of natural killer (NK) cells in the 1980s based on their 'natural killing' activity against cancer cells, accumulating evidence has now established that NK cells are key effectors in cancer immunosurveillance. ${ }^{1-4}$ They are innate lymphoid cells with an intrinsic selectivity and capacity to kill cancer cells over normal healthy cells without the requirement for prior sensitization, which is distinct from the activation of adaptive immune cells. ${ }^{3}$ Accordingly, NK cells are in the 'ready-to-kill' state and rapidly trigger effector functions against cancerous cells that involve the direct cytolysis and secretion of cytokines, including interferon- $\gamma($ IFN- $\gamma$ ) and tumor-necrosis factor- $\alpha$ (TNF- $\alpha) .{ }^{1}$ Due to their innate selectivity against cancer cells, NK cells are now being considered promising therapeutic measures in the treatment of cancer. In support, numerous studies have demonstrated that NK cell functional deficiency is associated with an increased risk of developing various types of cancer, ${ }^{5-7}$ including a seminal 11-year follow-up study reporting the high risk of cancer incidence in subjects with low NK cell cytotoxic activity. ${ }^{8}$ Moreover, NK cell effector functions are often impaired in patients suffering from various types of cancer, ${ }^{9-14}$ and the extent of such dysfunction correlates with clinical prognosis. ${ }^{15-17}$ Thus, NK cell effector function can be regarded as a surrogate marker of ongoing antitumor immune response, and its monitoring can be utilized as a reliable prognostic biomarker. ${ }^{18}$ Thus, these findings raise an interesting possibility that an infusion of NK cells without functional deficiency or reviving of endogenous NK cell function hold promise in the treatment of cancer.

NK cells are equipped with an array of germline-encoded surface receptors that recognize specific ligands on target cells and use diverse receptor combinations to deliver selective

\footnotetext{
${ }^{1}$ Department of Biomedical Sciences, Asan Medical Center, University of Ulsan College of Medicine, Seoul, Korea; ${ }^{2}$ Department of Microbiology, Asan Medical Center, University of Ulsan College of Medicine, Seoul, Korea; ${ }^{3}$ Department of Convergence Medicine, Asan Medical Center, University of Ulsan College of Medicine, Seoul, Korea and ${ }^{4}$ Asan Institute for Life Sciences, Asan Medical Center, University of Ulsan College of Medicine, Seoul, Korea Correspondence: Professor N Kim, Department of Convergence Medicine, Asan Institute for Life Sciences, Asan Medical Center, University of Ulsan College of Medicine, 88 Olympic-ro 43-gil, Songpa-gu, Seoul 05505, Korea.

E-mail: naykim@amc.seoul.kr

or Professor HS Kim, Department of Biomedical Sciences, Asan Medical Center, University of Ulsan College of Medicine, 88 Olympic-ro 43-gil, Songpa-gu, Seoul 05505, Korea.
}

E-mail: hunkim@amc.seoul.kr

Received 1 December 2016; accepted 15 December 2016 
cytotoxicity against cancer cells. ${ }^{3,19}$ To prevent the killing of normal healthy cells, NK cells primarily use inhibitory receptors, such as killer cell Ig-like receptors (KIRs) and CD94NKG2A, that bind to major histocompatibility complex (MHC) class I molecules on target cells. ${ }^{20}$ In addition, NK cells require combined signals from multiple activating receptors to elicit effective cytotoxicity against cancer cells. Thus, the decision of an NK cell to kill target cells is determined by a signaling balance between activating and inhibitory receptors. In this context, cancer cells can be sensed and killed by NK cells through the loss of MHC class I molecules, which are constitutively present on normal healthy cells and/or upregulation of various 'stress-induced' ligands for NK cell activating receptors that are usually sparse on healthy cells. ${ }^{21-23}$

Given the multitude of activating receptors that bind endogenous 'self' ligands on target cells, NK cell activation is tightly regulated and kept in check by the requirement for the engagement of multiple activating receptors. Except for CD16-mediated antibody-dependent cellular cytotoxicity, NK cell effector functions are rarely triggered by engaging a single activating receptor on human, freshly isolated resting NK cells. Rather, their activation requires the co-engagement of specific pairs of activating receptors with distinct signaling properties. $^{3,24,25}$ For example, NKG2D, 2B4, DNAM-1 and NKp46, which are not activating on their own, can induce the synergistic activation of NK cells in combination with their partner receptors. ${ }^{26}$ Such redundancy of receptor synergy and its intersection by a single class of inhibitory receptor containing immunoreceptor tyrosine-based inhibition motifs suggests common checkpoints for NK cell activation. Thus, understanding how signals from different activating receptors converge on common molecular checkpoints is important and may provide innovative strategies that enhance NK cell activation for cancer immunotherapy. Moreover, upon exposure to cytokines (for example, interleukin (IL)-2 or IL-15), NK cells have enhanced survival and reactivity toward target cells. Such cytokine stimulation lowers the threshold for NK cell activation and thereby renders NK cells responsive to a single activating receptor (for example, NKG2D) to trigger effector functions. ${ }^{26-29}$ In this context, cytokine preactivation of NK cells may provide an additional strategy for NK cell-based cancer immunotherapy. Recent studies have also suggested that NK cell activation relies on the modulation of other molecular checkpoints (for example, DGK $\zeta$, CIS, PI3K $\gamma$ ) and microRNA (miRNA). Initially developed for T-cell-based therapy, blockade of immune checkpoints (for example, PD-1) and chimeric antigen receptors (CARs) also show promising results when applied to NK-cell-based cancer therapy. Due to our advanced understanding of NK cell activation, many efforts have been made to enhance the therapeutic benefit of NK cells via manipulation of effector functions. In this review, we describe recent progress in NK cell activation and discuss therapeutic strategies targeting NK cells, with a focus on common signaling checkpoints for different activating receptors.

\section{COMMON SIGNALING CHECKPOINTS FOR NK CELL} ACTIVATION

Compared to $\mathrm{T}$ cells that are dominantly activated by immunoreceptor tyrosine-based activation motif (ITAM)coupled TCR, NK cells have a multitude of receptors with different ligand specificity and signaling properties for activation: ${ }^{3,30-32}$ receptors associated with ITAM-bearing molecules (for example, CD16, NKp30, NKp46), the DAP10-associated receptor NKG2D, receptors of the signaling lymphocytic activation molecule family (for example, 2B4) and other activating receptors (for example, DNAM-1). Among the three ITAM-bearing adaptor molecules, $\mathrm{FcR} \gamma$ and $\mathrm{CD} 3 \zeta$ chains associate with CD16, NKp30 and NKp46 receptor by forming either homodimers or heterodimers, whereas DAP12 associates with the NKp44 receptor. The signaling properties of ITAMassociated receptors in NK cells are considered similar to those mediated by TCR or BCR. ${ }^{30}$ NKG2D associates with DAP10, which harbors the YINM motif and signals via the recruitment of phosphatidylinositol-3-kinase (PI3K) or Grb2-Vav1 complex. ${ }^{33}$ Engagement of NKG2D triggers activation of Akt and MAPK, Erk and Jnk. 2B4 contains an immunoreceptor tyrosine-based switch motif and signals through the adaptor SAP, which recruits tyrosine kinase Fyn. ${ }^{34-36}$ 2B4 signaling involves the activation of Vav1, Erk, p38 MAPK and PLC- $\gamma 2$. In SAP deficiency, 2B4 could function as an inhibitory receptor by recruiting protein tyrosine phosphatases (for example, SHIP-1). ${ }^{35,37,38}$ DNAM-1 harbors an immunoreceptor tyrosine tail-like motif and signals via the recruitment of Grb2, resulting in Vav1, PI3K-Akt, Erk and PLC- $\gamma 1$ activation. ${ }^{39}$ Given various receptor combinations that trigger the synergistic activation of NK cells, signals from different activating receptors must converge on certain points at which synergy occurs. Using an activation model that combines 2B4 with NKG2D or DNAM-1, we found that SLP-76-Vav1 and NF-кB p65 function as common checkpoints for multiple activation pathways in NK cells (Figure 1). ${ }^{40,41}$ In addition, we recently provided evidence demonstrating E3 ubiquitin ligase c-Cbl and glycogen synthase kinase (GSK)-3 $\beta$ as negative regulators of NK cell activation triggered by multiple activating receptors (Figure 1). ${ }^{25,42}$ Because cancer cells express various and heterogeneous ligands for NK activating receptors, it would be desirable to target and modulate signaling molecules that are common to multiple activating receptors for NK cell activation.

\section{Integration of activation signals by SLP-76-Vav1}

It has been established that Vav proteins play critical and non-redundant roles in the activation of NK cells. ${ }^{3}$ Vav protein deficiency is associated with severe defects in triggering $\mathrm{Ca}^{2+}$ responses and NK cell functions in response to multiple activating receptors. ${ }^{4-47}$ Among the three Vav isoforms, Vav1 is critical for the synergistic combinations of NKG2D, 2B4 and DNAM-1. ${ }^{25}$ In support, Vav1 is commonly activated by phosphorylation via the engagement of NKG2D, 2B4 or DNAM-1. However, enhanced and additive phosphorylation of Vav1, which is required for synergistic activation, is achieved by the combination of NKG2D with $2 \mathrm{~B} 4$ but not with 


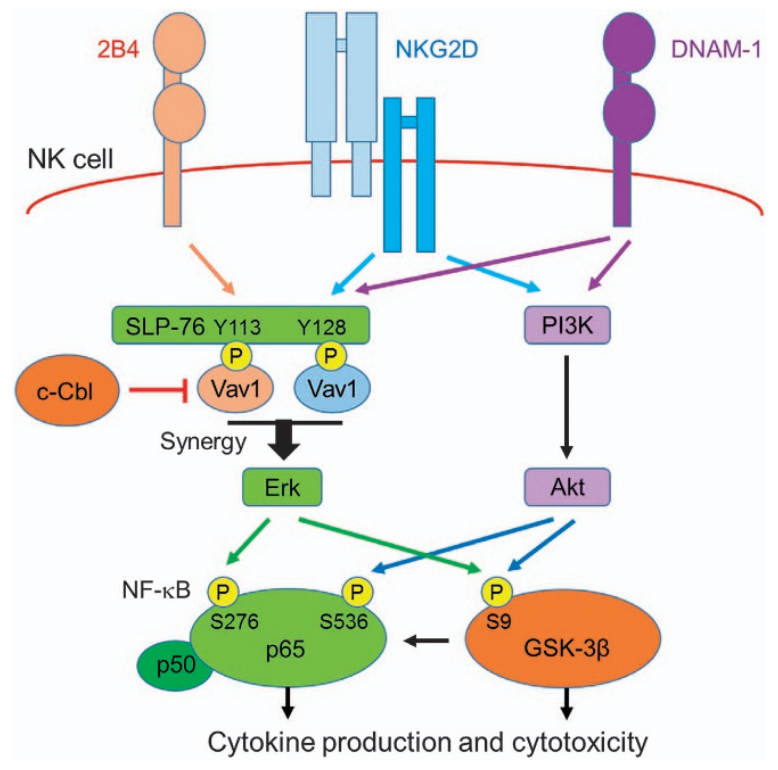

Figure 1 Molecular checkpoints for NK cell activation through different activating receptors. Synergistic activation of a NK cell requires the engagement of a specific combination of activating receptors, such as 2B4 with NKG2D or DNAM-1. These combinations induce complementary phosphorylation of SLP-76, resulting in Vav1-dependent synergistic activation of PLC- $\gamma 2$ and Erk. Vav1 activation by the synergistic combination of receptors can overcome the intrinsic inhibition by c-Cbl. NKG2D or DNAM-1 triggers another independent signal through $\mathrm{PI} 3 \mathrm{~K}$ and Akt. Synergistically activated Erk signal and separate Akt signal cooperatively induce inhibitory phosphorylation at serine 9 of GSK-3 $\beta$ or independently induce synergistic phosphorylation at serine 276 and serine 536 of NF-kB p65, respectively. Vav1 activation under the licensing of SLP-76 phosphorylation regulates downstream p65 phosphorylation and NF-кB activation, which prevents inadvertent NF-KB activation and ensures proper activation. These elaborate mechanisms coordinate to achieve the synergistic activation of NK cell effector functions.

DNAM-1. This finding suggests the presence of an upstream regulatory element for signal integration, which results in optimal Vavl activation. We found that signals from synergizing receptors converge on the adaptor protein $\mathrm{SH} 2$ domaincontaining leukocyte phosphorylation of $76 \mathrm{kDa}$ (SLP-76) via complementary phosphorylation of two tyrosine residues in SLP-76. ${ }^{40}$ Each one of the two phosphorylated tyrosines, which constitute separate binding sites for Vavl, is required for the synergistic activation of NK cells. Signaling by NKG2D and DNAM- 1 leads to the same phosphorylation of SLP-76 at tyrosine 128, whereas 2B4 signals for phosphorylation at tyrosine 113. In this respect, complementary phosphorylation of SLP-76 is achieved by the synergistic combination of 2B4 with NKG2D or DNAM-1 but not by the non-functional combination of NKG2D with DNAM-1. Interestingly, the selective phosphorylation of tyrosine 113 and tyrosine 128 in SLP-76 is unique to signaling by natural cytotoxicity receptors, as stimulation of NK cells by CD16, and of T cells by TCR resulted in phosphorylation at both sites. Thus, complementary phosphorylation of SLP-76, which results in Vav1-dependent synergy, could represent a molecular checkpoint for NK cell activation via multiple activating receptors.

\section{Integration of activation signals by NF-кB p65}

The transcription factor NF- $\mathrm{KB}$ plays a key role in determining the outcomes of diverse immune responses ${ }^{48,49}$ and is also an indispensable component of NK cell cytotoxicity and cytokine production. ${ }^{50,51}$ However, how NF- $\mathrm{kB}$ activation is controlled by multiple activating receptors during NK-target cell contact remains largely unclear, and previous studies have been confined to a few activating receptors that are coupled to ITAM-bearing molecules whose signaling properties are similar to those triggered by the antigen-specific receptors of the adaptive immunity. ${ }^{52,53}$ Effective activation of cytotoxicity and cytokine secretion by human NK cells requires a combination of synergistic receptors. Among activating receptors NKG2D, 2B4 and DNAM-1, which are non-ITAM receptors that couple to different signaling modules, no single activating receptor is competent for NF- $\mathrm{kB}$ activation. Rather, their synergistic combination is required for effective NF- $\mathrm{\kappa B}$ activation and NK cell responses. ${ }^{41}$ This combination relays independent and complementary signals that result in the combined phosphorylation of the 'upstream' SLP-76-Vav1 and unexpectedly, the 'downstream' NF-кB p65 subunit. Vav1-dependent synergistic signals are required for $\mathrm{p} 65$ phosphorylation and NF- $\mathrm{\kappa B}$ activation, which is supported by the stepwise regulation of Vav1 and p65 phosphorylation in NK cells. Thus, NF- $\kappa B$ activation in NK cells is coordinately regulated by the complementation of activating receptors with distinct signaling properties to support appropriate and effective NK cell responses.

\section{c-Cbl as a gatekeeper for NK cell activation}

$\mathrm{Cbl}$ proteins, including $\mathrm{c}-\mathrm{Cbl}$ and $\mathrm{Cbl}-\mathrm{b}$, are multifunctional adaptor molecules harboring E3 ubiquitin ligase activity, which primarily represses signaling by lymphocyte receptors. ${ }^{54-57}$ Such negative regulation is largely mediated by promoting the ubiquitylation of signaling molecules, which can result in internalization from the cell surface and delivery to lysosomal or proteasomal degradation. In mice, $\mathrm{c}$ - $\mathrm{Cbl}$ is required for proper T-cell development by inhibiting TCR signals through ubiquitylation of the TCR $\zeta$ chain $^{58,59}$ and Vav1, ${ }^{60}$ and by promoting internalization of LAT. ${ }^{61}$ By comparison, peripheral T-cell activation is regulated by Cbl-b through ubiquitylation, but not degradation, of the p85 subunit of PI3K.62,63 In our study of human NK cells, c-Cbl but not Cbl-b, imposes a threshold for NK cell activation. ${ }^{25}$ Knockdown of c-Cbl but not Cbl-b enhances NK cell cytotoxicity and cytokine secretion through multiple activating receptors by promoting the Vav1-dependent activation pathway. An interesting outcome of $\mathrm{c}-\mathrm{Cbl}$ knockdown is that it removes the requirement for synergy and renders NK cells responsive to the engagement of a single activating receptor, such as NKG2D and $2 \mathrm{~B} 4$. These data suggest that c-Cbl serves as a gatekeeper for NK cell activation via different activating receptors. Although c-Cbl 
knockdown amplifies the signal input from an individual activating receptor (for example, NKG2D), it cannot replace the requirement for complementary signals from the partner receptor (for example, 2B4) for full NK cell activation. In support, $\mathrm{Cbl}$ knockdown markedly enhances NF- $\mathrm{KB}$ activation and cytokine production by the co-engagement of NKG2D and 2B4, but not by a single receptor. ${ }^{41}$ This 'quantitative' regulation of signaling by c-Cbl may help to prevent the inadvertent activation of NK cells toward normal healthy cells that express limited ligands for the NK cell activating receptor. In this respect, c-Cbl modulation would provide a promising therapeutic strategy to enhance NK cell activation toward cancer cells. In a recent study, Cbl-b deficiency was shown to enhance anti-metastatic activity of NK cells and efficiently reduce metastases of murine mammary cancer and melanoma. ${ }^{64}$ Thus, targeting Cbl-b would be an interesting strategy to enhance the anti-cancer activity of NK cells, although its therapeutic potential in human NK cells requires further investigation.

\section{GSK-3 $\beta$ as a negative regulator of NK cell activation}

Using a model of NK cell activation that is dependent on combined signals from different receptors (for example, NKG2D and 2B4), GSK-3 was identified as a common signaling molecule in NK cell activation by multiple activating receptors. ${ }^{42}$ GSK-3 is a serine/threonine protein kinase that serves as a convergent point downstream of diverse signaling pathways and regulates many cellular processes including immune responses. ${ }^{65,66}$ In our study, GSK-3, particularly GSK-3 $\beta$, negatively regulates NK cell effector functions, such as cytotoxicity and cytokine production triggered by multiple activating receptors. ${ }^{42}$ Of interest, such negative regulation by GSK-3 $\beta$ is common to diverse activation pathways downstream of both ITAM-coupled (for example, NKp30, CD16) and nonITAM-coupled (for example, NKG2D, 2B4) receptors. Furthermore, the kinase activity of GSK-3 $\beta$ is directly involved in the repression of NK cell function, indicating GSK- $3 \beta$ as a potential therapeutic target to enhance NK cell activation. In support, knockdown of GSK-3 $\beta$ or its inhibition with different pharmacological inhibitors augments NK cell activation through diverse activating receptors. Mechanistic studies have revealed an association between GSK-3 $\beta$ inhibition and an increase in calcium mobilization and activation of Akt and Erk, which are required for NK cell activation. Thus, GSK-3 $\beta$ appears to function as a checkpoint molecule for diverse activation pathways in NK cells. In a recent study, GSK-3 overexpression was observed in NK cells from acute myeloid leukemia (AML) patients, which can account for AML-NK dysfunction. ${ }^{67}$ Genetic or pharmacological GSK3 inactivation restores AML-NK cell cytotoxicity. Mechanistic studies have demonstrated that the potentiation of NK cell function after GSK-3 inhibition is linked to enhanced NF- $\mathrm{KB}$ activation and conjugate formation. Given the involvement of GSK-3 in multiple activation pathways, targeted repression of GSK-3 may provide a promising therapeutic strategy for NK-cell-based cancer therapy.

\section{OTHER THERAPEUTIC CHECKPOINTS FOR NK CELL ACTIVATION}

A recent report has shown that diacylglycerol kinase (DGK) $\zeta$-deficiency enhances NK cell function, such as cytokine production and degranulation, in an ERK-dependent manner in mice. ${ }^{68}$ DGK $\zeta$-deficient mice reject tumors more efficiently in vivo. However, the mice have normal NK cell development, including inhibitory NK cell receptor expression or function. DGK $\zeta$ is a negative regulator of diacylglycerol-mediated signaling. DGK $\zeta$ is initially known to be expressed in macrophages and dendritic cells, regulating microbial recognition. ${ }^{69}$ DGK $\zeta$ limits the generation of natural regulatory $\mathrm{T}$ cells (Tregs) by suppressing their development. ${ }^{70,71}$ Thus, inhibiting DGK $\zeta$ in vivo should be carefully investigated for cancer immunotherapy.

Cytokine-inducible SH2-containing protein (CIS) is suggested as a novel checkpoint in NK-cell-mediated tumor immunity by regulating IL-15 signaling in NK cells. ${ }^{72}$ The gene encoding CIS, cish, is rapidly induced by IL-15 and deletion of cish rendered NK cells hypersensitive to IL-15. Interestingly, Cish-/- mice are resistant to various cancer metastases in vivo, due to NK cells intrinsically. Without CIS, JAK-STAT signaling is increased in NK cells. CIS also actively silences TCR signaling in $\mathrm{CD}^{+} \mathrm{T}$ cells to maintain tumor tolerance. ${ }^{73}$ Taken together, inhibiting CIS may improve anti-cancer effect by dual mechanisms: to promote NK cells and cytotoxic T cells together.

The roles of PI3K $\gamma$ and $\delta$ isoforms have been extensively investigated in NK cell function and development. ${ }^{74,75}$ In particular, $\mathrm{PI} 3 \mathrm{~K} \gamma$ plays a role in IFN- $\gamma$ production and migration of NK cells. ${ }^{74,76}$ Recently, PI3K $\gamma$ has been suggested as a molecular switch that controls immune suppression to overcome resistance to checkpoint blockade therapy. ${ }^{77,78}$ PI3K $\gamma$-specific inhibitor (IPI-549 by Infinity) is undergoing phase $1 / 1 \mathrm{~b}$ clinical trials for advanced solid tumors. Thus, there is an urgent need to re-evaluate the role of PI3K $\gamma$ in NK cells.

\section{CYTOKINE STIMULATION FOR NK CELL ACTIVATION}

NK cells require cytokines (for example, IL-2, IL-12 and IL-15) to develop, proliferate and function optimally. Therefore, injection of cytokine(s) to boost endogenous NK cells has been a therapeutic option. IL-2 is one of the quintessential cytokines required for NK cells to survive and proliferate, but high toxicity shown in early studies have motivated researchers to evaluate the efficacy of low-dose IL-2. ${ }^{79,80}$ Ultra-low dose of IL-2 (100 000-200 $000 \mathrm{IU} \mathrm{m}^{-3}$, compared with low dose of $300000-3000000 \mathrm{IU} \mathrm{m}^{-3}$ ) was tested for safety and has been shown to increase NK cells in healthy volunteers. ${ }^{81}$ It is also suggested that IL-2 prevents graft-versus-host disease (GVHD) by an expansion of Treg cells without diminishing antiviral and anti-leukemic activity in humans. ${ }^{82}$ Recently, genetically engineered IL-2 molecules have been developed to circumvent the toxicity and expansion of Tregs. One such molecule is a mutant IL-2 (F42K), which binds to the IL-2 receptor (IL-2R) $\beta \gamma$ with lower affinity. IL-2 (F42K) induces the expansion of Treg cells, but promotes NK cell activation in a mouse melanoma 


\section{Tumor cell/DC/Treg}

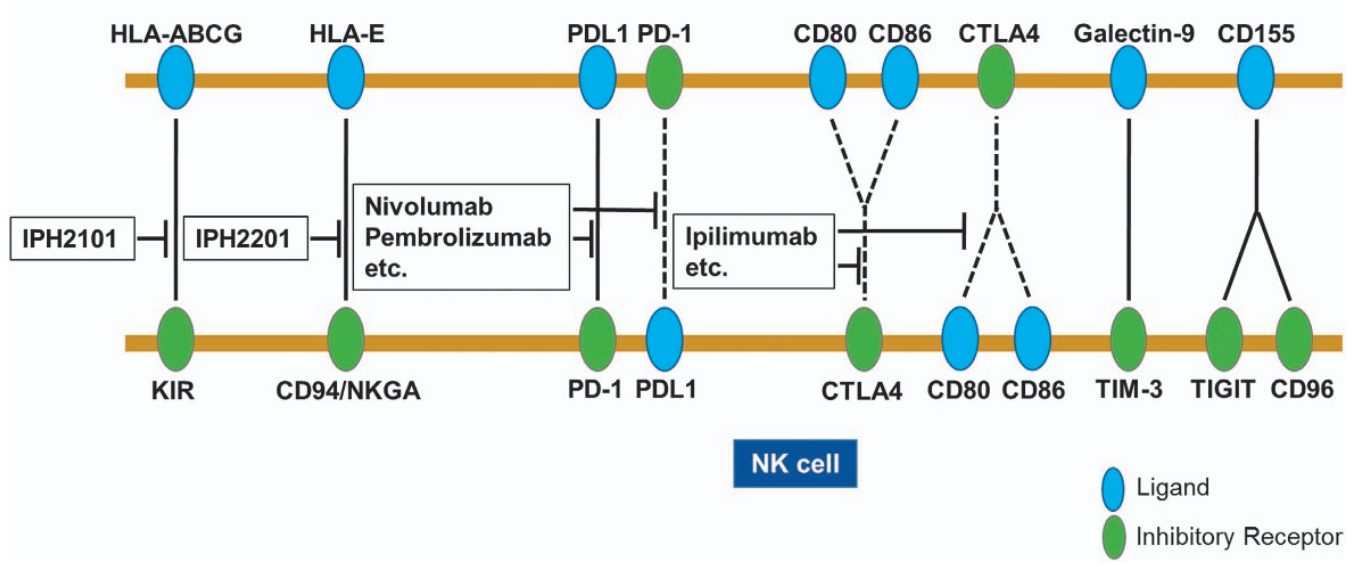

Figure 2 Interactions of immune checkpoint receptors and ligands affecting NK cell functions. NK cells (bottom) express multiple immune checkpoint receptors and ligands. The green color represents receptors and the blue color represents ligands. The ligands on tumor cells are well known to interact with their cognate receptors on NK cells, but it has been reported that ligands on NK cells also interact with their receptors on dendritic cells (DCs) or Tregs; for example, PD-1 on DCs and CTLA-4 on Tregs. However, the effects of the interactions on anti-tumor activity of NK cells may require further confirmation. The dotted lines indicate that the interactions may require further investigation, whereas the interactions marked with solid lines are less debatable. The names in the boxes (middle) show blocking agents that are currently available in clinic.

model. ${ }^{83}$ Another molecule is a recombinant fusion protein consisting of an NKG2D binding protein and a mutated form of IL-2 with poor affinity for IL-2R $\alpha$. This protein exhibits potent anti-tumor effect in a murine lung cancer model. The recombinant fusion protein expands and activates NK cells but not Tregs. ${ }^{84}$ Nevertheless, the capacity of IL-2 to augment Tregs is still a major concern in immunotherapy, although Tregs help to prevent GVHD. However, ultralow doses of long-lived IL-2 induce prolonged increases in Tregs in non-human primates. ${ }^{85}$

IL-15 plays a role in NK cell development. Its receptor shares a common $\gamma$ chain as a subunit with IL-2R, as well as a $\beta$-chain, but has a unique stimulation mechanism of trans-presentation. ${ }^{86}$ Heterodimeric IL-15 molecules with more potency or longer half-life have been developed to avoid the needs for trans-presentation. ${ }^{87,88}$ They enhanced anti-tumor activity by $\mathrm{NK}$ and $\mathrm{CD} 8+\mathrm{T}$ cells in vitro and in a murine melanoma model. Phase I clinical trials using recombinant human hetIL-15 (IL-15/sIL-15Ra) are in progress, but an IL-15 superagonist has exhibited significant immunotoxicity. ${ }^{89}$ Another recombinant IL-15 is an IL-15-N72D superagonistcomplexed with IL-15R $\alpha$ Sushi-Fc fusion protein, which enhances subpopulations of NK and memory CD8+ T cells, and mediates antitumor activity in mouse breast and colon cancer models. ${ }^{90}$ The last molecule is undergoing clinical trials. It is well known that NK cells can be stimulated by IL-12 in combination with IL-2 to express cytokines and chemokines and to migrate. ${ }^{91}$ In addition, IL-12 and IL-18 proliferate and synergistically activate murine NK cells..$^{92}$ It was hence a good candidate for cancer immunotherapy, but unfortunately, the results from clinical trials have not fulfilled the hoped-for outcomes. ${ }^{93}$
Furthermore, protocols have been developed to expand NK cells ex vivo using cytokine cocktails for infusion. Cytokine-induced memory-like NK cells with enhanced survival and functionality have been generated by preactivation with IL-12, IL-15 and IL-18 in a humanized mouse model. ${ }^{94}$ To improve the ex vivo expansion of NK cells, feeder cells are often used. Recent reports have described clinical trials with ex vivo expanded NK cells using irradiated $\mathrm{K} 562$ cells that have been genetically modified to express 41BB-ligand and IL-15 or using the same cells expressing not only 41BB-ligand but also membrane-bound IL-15. NK cells were activated and proliferated in vivo in both cases. The former study showed GVHD in five out of nine solid tumor patients, following T-cell-depleted allogeneic hematopoietic stem cell transplantation. ${ }^{95}$ However, the latter reported no serious adverse events in multiple myeloma patients. ${ }^{96}$ Importantly, the patients were administered IL-2 following NK cell infusion in the latter study but not in the former. In summary, there has been much development in cytokine treatment to enhance $\mathrm{NK}$ cells and ex vivo expansion of NK cells, but the optimization of cytokines for cancer immunotherapy awaits further preclinical and clinical research.

\section{IMMUNE CHECKPOINT INHIBITORS FOR NK CELL ACTIVATION}

The most promising and discussed new development in cancer immunotherapy is the blockade of immune checkpoints and CARs. These studies are focused on cytotoxic $\mathrm{T}$ cells rather than NK cells in most cases, but the technologies are also readily applicable to NK cells. NK cells kill cancer cells as cytotoxic $\mathrm{T}$ cells and have advantages in contexts that lack MHC restriction. 
Recent progress in the blockade of immune checkpoints have mostly focused on Programmed cell death protein 1 (PD-1) and Cytotoxic T-lymphocyte-associated protein 4 (CTLA-4) (Figure 2). There are three FDA-approved drugs to inhibit PD-1 or CTLA-4 pathways. ${ }^{97}$ Ipilimumab is a human IgG1 antibody $(\mathrm{Ab})$ used for CTLA-4 blockade. Nivolumab is a human IgG4 Ab specific for PD-1. Both were developed by Bristol-Myers Squibb. Pembrolizumab by Merck (Kenilworth, NJ, USA) is a humanized IgG4 Ab directed against PD-1. More immune checkpoint inhibitors are currently in clinical trials. PD-1 is highly expressed on approximately one-fourth of peripheral blood NK cells in healthy humans. It is expressed by $\mathrm{CD} 56^{\mathrm{dim}} \mathrm{NKG} 2 \mathrm{~A}^{-} \mathrm{KIR}^{+} \mathrm{CD} 57^{+}$ mature NK cells, but not by CD56 ${ }^{\text {bright }} \mathrm{NK}$ cells. ${ }^{98} \mathrm{PD}-1+$ NK cells are likely resting NK cells. ${ }^{99} \mathrm{PD}-1$ is upregulated on NK cells from Kaposi sarcoma patients, mediating impaired NK cell function. ${ }^{100}$ Treatment with an anti-PD-1 Ab enhances human NK cell cytotoxicity against autologous multiple myeloma cells in vitro. ${ }^{101}$ CTLA-4 itself is expressed by activated mouse NK cells and inhibits cytokine production in response to mature dendritic cells. ${ }^{102}$ The expression of the CTLA-4 and CD28 ligands CD80 and CD86 on cancer cells enhance the cytotoxicity of human NK cells. ${ }^{103}$ CTLA- ${ }^{+}$Tregs suppress NK cell cytotoxicity in Cetuximab (anti-EGFR Ab)treated head and neck cancer patients. ${ }^{104}$ However, it has been proposed that B7.1-CD28/CTLA-4 is not involved in triggering human NK cell activation in a previous study. ${ }^{105}$ Furthermore, CD28/B7 co-stimulation does not appear to play an important role in peripheral $\mathrm{NK}$ cells in murine cytomegalovirus infection. ${ }^{106}$ Taken together, it remains unclear whether antiCTLA-4 therapy could improve the anti-cancer effect of NK cells.

NK cells express multiple inhibitory receptors, such as KIRs, CD94/NKG2A, T-cell immunoglobulin- and mucin-domaincontaining molecule 3 (TIM-3), and T-cell immunoreceptor with Ig and immunoreceptor tyrosine-based inhibition motif domains (TIGIT), although their potential as therapeutic targets has been much less studied. However, the role of KIRs in NK cell activation and licensing is well established. The 'missing self' hypothesis is that NK cells recognize target cells by the absence of self-MHC class I molecules, in which receptors on NK cells are inhibitory KIRs in humans. An anti-KIR Ab (IPH2101 by Innate Pharma, Marseille, France) has been proven to be safe without toxicity and autoimmunity in multiple myeloma and AML patients. ${ }^{107,108}$ However, the efficacy was different; IPH2101 enhances ex vivo NK cytotoxicity in multiple myeloma patients, but in AML patients, there were no significant differences in $\mathrm{NK}$ cell number and cytotoxicity. CD94/NKG2A is a C-type lectin receptor, in which the ligand is HLA-E. The first phase I/II clinical trial is on-going and employs an anti-NKG2A Ab (IPH2201 by Innate Pharma) since 2015.

The expression of TIM-3, whose cognate ligand is galectin-9, is upregulated in peripheral $\mathrm{NK}$ cells from advanced gastric cancer patients ${ }^{109}$ and from lung adenocarcinoma patients, ${ }^{110}$ suggesting the value of TIM-3 as a predictive or prognostic biomarker. It is also expressed in the tumor-infiltrated NK cells in $75 \%$ of patients with gastrointestinal stromal tumor. ${ }^{111}$ Interestingly, TIM- $3^{+}$tumor-infiltrated NK cells do not express PD-1. Inhibition of TIM/Gal-9 interaction by Abs was evaluated in vitro. Exhausted NK cells from advanced melanoma patients were rescued by anti-TIM-3 blocking Ab. ${ }^{112}$ They also found that TIM-3 expression levels are correlated with disease stages. However, blockade by anti-Gal-9 Ab reduced IFN- $\gamma$ production in NK cells from healthy donors in response to primary AML blasts. ${ }^{113}$ TIGIT and CD96 are inhibitory receptors that compete with DNAM-1 (CD226), an activating receptor, for CD155 as their common ligand. CD155 is highly expressed on many types of tumor cells. Blockade of CD96 or TIGIT with mAbs has been shown to improve anti-tumor activity in mice. ${ }^{114}$ In particular, the combined blockade of TIGIT and PD-1 showed significant tumor clearance. ${ }^{115}$ Similar to most immune checkpoint molecules, CD96 and TIGIT are expressed on cytotoxic T cells, as well as on NK cells. Thus, the effect of the blockade involves the enhancement of cytotoxic T cells as well.

\section{CAR/BIKE/TRIKE FOR NK CELL ACTIVATION}

The initial idea behind CAR was to overcome MHC-restriction of $\mathrm{T}$ cells, which enables allogeneic $\mathrm{T}$-cell infusion, and to reduce the risks of GVHD, as well as to increase the number of tumor antigen-specific $\mathrm{T}$ cells and receptor affinities. CAR is designed to replace the antigen-binding site of TCR with the antigen-binding site of an immunoglobulin with high affinity and specificity to an antigen and without MHC-restriction. Transmembrane and cytosolic signaling domains of $\mathrm{CD} 3 \xi$ and co-stimulatory motifs (for example, CD28, 4-1BB and OX40) are linked to transmit signals to $\mathrm{T}$ cells. Consequently, CAR-activated $\mathrm{T}$ cells efficiently remove tumor cells using cytolytic molecules, such as perforin and granzymes. $\mathrm{T}$ cells and NK cells share some elements of activating signaling pathways, and designing NK-specific signaling domains may improve CAR-NK cell therapy. NK cells tend to have shorter lives than $\mathrm{T}$ cells. Thus, it might be advantageous, regarding the potential side-effects and off-target effects of long-lived CAR-T cells. It is no surprise that many researchers have attempted to produce CAR-NK cells. ${ }^{2,116}$ Some of these studies exploit established NK cell lines, such as NK-92 cells, but approval may be difficult due to the potential safety issues of the established cell lines. All the published results using established NK cell lines are preclinical, but clinical trials are following soon. A single institution, phase I trial (NCT00995137) in children with B-cell acute lymphoid leukemia was performed to investigate the safety of donor NK cells bearing CD19-specific CARs, but the results have not yet been published. Phase II clinical trial is on-going in B-cell acute lymphoid leukemia patients using donor NK cells at the present (NCT 01974479). Well-defined tumor-specific antigens are a prerequisite for $\mathrm{CAR}$, and it is therefore difficult to develop CAR for certain cancers for which no tumor-specific antigens are known. In conclusion, CAR-NK cells are very promising for cancer immunotherapy as a single agent or in 
combination with CAR-T cells, but they may require the discovery of novel tumor-specific antigens as well as an adaptation of techniques specifically to NK cells, such as evaluating better signaling domains for NK cells.

Since the great success of the first ever anti-tumor antibody, Rituximab (Roche, Basel, Switzerland), antibodies (Abs) have been an indispensable component of standard anti-tumor regimens. Rituximab is a chimeric (mouse and human) monoclonal $\mathrm{Ab}$ specific to $\mathrm{CD} 20$, and functions as a marker for B-cell lymphoma and leukemia. The effector functions of the $\mathrm{Ab}$ are complement-dependent cytotoxicity and antibodydependent cellular cytotoxicity. The latter is mediated by the Fc receptor on NK cells and macrophages. CD16 is the Fc receptor on NK cells. However, not all Abs can remove or reduce targeted tumors, and thus efforts have been made to improve therapeutic Abs. Bispecific Abs were initially developed by chemical cross-linking and the technique was soon replaced by fusion with peptide linkers or by genetic engineering to facilitate the proximity between cytotoxic $\mathrm{T}$ cells or macrophages and tumor cells. ${ }^{17-120}$ When the bispecific $\mathrm{Ab}$ detects $\mathrm{T}$ cells, it is called a bispecific T-cell engager (BiTE); the bispecific Ab detects NK cells and is therefore called a bispecific killer cell engager (BiKE). Several preclinical studies have been published, although there are no current clinical trials. CD16/ CD19 BiKE and CD16/CD19/CD22 TriKE were generated to target $\mathrm{CD} 19^{+} \mathrm{B}$-cell lymphoma and leukemia. ${ }^{121}$ They trigger NK cell activation and cytotoxicity in vitro. CD22 is a B-cell coreceptor with an immunoreceptor tyrosine-based inhibition motif and is involved in the negative regulation of $\mathrm{B}$-cell function. More recently, CD16/CD133 BiKE is produced to target colorectal cancer. ${ }^{122}$ BiKE enhances NK cytotoxicity in vitro. CD16/CD33/IL-15 TriKE was developed to target AML. ${ }^{123}$ TriKE is incorporated a novel modified human IL-15 crosslinker to CD16/CD33 BiKE. TriKE induces better anti-tumor activities than a CD16/CD33 BiKE in a xenograft model using HL-60 human AML cells. Abs can deplete, activate or block, with high affinity, high specificity and MHC-independence. Thus, the application of Abs is versatile and promising for cancer immunotherapy.

\section{MIRNAS FOR NK CELL ACTIVATION}

miRNAs are non-coding RNAs of 18-22 nucleic acids, which often function as post-transcriptional regulators. Many miRNAs have been discovered to regulate NK cell development and function. ${ }^{124}$ In this review, we were particularly interested in several miRNAs that regulate cytotoxicity or immune checkpoints, as they could be developed as cancer immunotherapeutics. miR-27a is one of the first miRNAs discovered to target cytotoxicity of NK cells. ${ }^{125}$ miR-27a was identified as a suppressor of both Prf1 and GzmB mRNA in response to IL-15 from human miRNA microarray data. The same group also revealed that miR-150 regulates the cytotoxicity of NK cells by targeting perforin- 1 in mice. ${ }^{126}$ In a human NK cell line, NKL cells, miR-30c-1 expression is decreased after DNAM-1 (CD226) cross-linking. ${ }^{27}$ Overexpression of miR-30c-1 promoted the cytotoxicity of the NK cells against hepatoma cell lines via an upregulation of transmembrane TNF- $\alpha$. The target gene of miR-30c- 1 is HMBOX1. TGF- $\beta$ induces miR-183 in human NK cells to repress DAP12 transcription/translation and reduces tumor cytolysis and abrogated perforin polarization to immune synapses. Taken together, these findings suggest that the modification of miRNA expression may enhance cytotoxicity and anti-tumor effect of NK cells.

Another possibility to improve NK cell therapy is to regulate the immune checkpoint using miRNAs. HLA-G, a ligand of inhibitory KIR2DL4, is known to be expressed at a high frequency in various cancer cells. Several miRNAs regulate HLA-G expression: miR-548q, miR628-5p and miR152. ${ }^{128,129}$ miR-548q and miR628-5p interact with the $3^{\prime}$ untranslated region of HLA-G directly and overexpression of these miRNAs enhanced NK-cell-mediated HLA-G-dependent cytotoxicity. ${ }^{128}$ HLA-G expression is upregulated and miR-152 is downregulated by HBV infection in human samples. ${ }^{129} \mathrm{HBV}$-infected hepatocarcinoma cells express more HLA-G and are resistant to NK cytotoxicity. CYLD, a negative regulator of NF- $\mathrm{KB}$ signaling, is a target of miR-362-5p in NK cells. ${ }^{130}$ Human peripheral NK cells express high levels of miR362-5p. Overexpression of miR362-5p enhances the expression of IFN- $\gamma$, perforin, granzyme B and CD107a in human primary NK cells. Thus, miRNAs may be used to boost NK cytotoxicity against cancer cells. To apply these results to clinical trials, efficient, safe and specific methods to deliver miRNAs to NK cells or cancer cells must be developed beforehand.

\section{CONCLUSION}

NK cells are innate immune cells but share certain properties with adaptive immune cells, such as memory responses. They have two key functions: cytotoxicity to the tumor and virusinfected cells and cytokine production, which bridges the innate and adaptive immune responses. In particular, NK cells can kill cancer cells efficiently without MHC-restriction and risk of GVHD. Thus, they have been explored as an attractive cell population for cancer immunotherapy since Ruggeri et al. showed that allogeneic NK cells could eliminate leukemia relapses without GVHD. ${ }^{131}$ Recent clinical studies have proven the usefulness of NK cell therapy for various cancer patients. ${ }^{132,133}$ For example, high-dose infusion $\left(2 \times 10^{8}\right.$ cells per $\mathrm{kg}$ ) of ex vivo cultured NK cells following haploidentical hematopoietic cell transplantation significantly reduced leukemia progression (74-46\%). ${ }^{134}$ However, the success is still limited, and thus there is an urgent need to improve cancer immunotherapy using NK cells. Current efforts for NK cellbased therapy have mainly relied on strategies that manipulate the function of inhibitory receptors. Recent progress in understanding the mechanisms of NK cell activation, including those regulated by diverse molecular checkpoints, has provided new and promising therapeutic strategies to optimize NK cell reactivity against cancer. Although therapeutic benefits of such strategies need to be assessed, the knowledge of the activation and stimulation of NK cells provides a firm basis for how to modify NK cell activities for better outcomes in the clinic. If we can better understand the mechanisms governing NK cell 
reactivity toward cancer, then this knowledge can be applied to the development of an optimal design for cancer immunotherapy by targeting NK cells either alone or in combination with other therapies.

\section{CONFLICT OF INTEREST}

The authors declare no conflict of interest.

\section{ACKNOWLEDGEMENTS}

This work was supported by Intelligent Synthetic Biology Center of the Global Frontier Project, funded by the Ministry of Education, Science and Technology (2013-0073185); Grants from the National Research Foundation of Korea (2016R1A2B4010300).

1 Morvan MG, Lanier LL. NK cells and cancer: you can teach innate cells new tricks. Nat Rev Cancer 2016; 16: 7-19.

2 Guillerey C, Huntington ND, Smyth MJ. Targeting natural killer cells in cancer immunotherapy. Nat Immunol 2016; 17: 1025-1036.

3 Long EO, Sik Kim H, Liu D, Peterson ME, Rajagopalan S. Controlling natural killer cell responses: integration of signals for activation and inhibition. Annu Rev Immunol 2013; 31: 227-258.

4 Vivier E, Tomasello E, Baratin M, Walzer T, Ugolini S. Functions of natural killer cells. Nat Immunol 2008; 9: 503-510.

5 Roder JC, Haliotis T, Klein M, Korec S, Jett JR, Ortaldo J et al. A new immunodeficiency disorder in humans involving NK cells. Nature 1980; 284: 553-555.

6 Sullivan JL, Byron KS, Brewster FE, Purtilo DT. Deficient natural killer cell activity in x-linked lymphoproliferative syndrome. Science 1980; 210: 543-545.

7 Gineau L, Cognet C, Kara N, Lach FP, Dunne J, Veturi U et al. Partial MCM4 deficiency in patients with growth retardation, adrenal insufficiency, and natural killer cell deficiency. J Clin Invest 2012; 122: 821-832.

8 Imai K, Matsuyama S, Miyake S, Suga K, Nakachi K. Natural cytotoxic activity of peripheral-blood lymphocytes and cancer incidence: an 11-year follow-up study of a general population. Lancet 2000; 356: 1795-1799.

9 Fauriat C, Just-Landi S, Mallet F, Arnoulet C, Sainty D, Olive D et al. Deficient expression of NCR in NK cells from acute myeloid leukemia: evolution during leukemia treatment and impact of leukemia cells in NCRdull phenotype induction. Blood 2007; 109: 323-330.

10 Pierson BA, Miller JS. CD56+bright and CD56+dim natural killer cells in patients with chronic myelogenous leukemia progressively decrease in number, respond less to stimuli that recruit clonogenic natural killer cells, and exhibit decreased proliferation on a per cell basis. Blood 1996; 88: 2279-2287.

11 Saito H, Osaki T, Ikeguchi M. Decreased NKG2D expression on NK cells correlates with impaired NK cell function in patients with gastric cancer. Gastric Cancer 2012; 15: 27-33.

12 Oka M, Mitsunaga H, Hazama S, Yoshino S, Suzuki T. Natural killer activity and serum immunosuppressive acidic protein levels in esophageal and gastric cancers. Surg Today 1993; 23: 669-674.

13 Schantz SP, Shillitoe EJ, Brown B, Campbell B. Natural killer cell activity and head and neck cancer: a clinical assessment. J Natl Cancer Inst 1986; 77: 869-875.

14 Hersey P, Edwards A, Honeyman M, McCarthy WH. Low natural-killer-cell activity in familial melanoma patients and their relatives. $\mathrm{Br} J$ Cancer 1979; 40: 113-122.

15 Coca S, Perez-Piqueras J, Martinez D, Colmenarejo A, Saez MA, Vallejo C et al. The prognostic significance of intratumoral natural killer cells in patients with colorectal carcinoma. Cancer 1997; 79: 2320-2328.

16 Takeuchi H, Maehara Y, Tokunaga E, Koga T, Kakeji Y, Sugimachi K. Prognostic significance of natural killer cell activity in patients with gastric carcinoma: a multivariate analysis. Am J Gastroenterol 2001; 96: 574-578.

17 Ishigami S, Natsugoe S, Tokuda K, Nakajo A, Che X, Iwashige H et al. Prognostic value of intratumoral natural killer cells in gastric carcinoma. Cancer 2000; 88: 577-583.
18 Viel S, Charrier E, Marcais A, Rouzaire P, Bienvenu J, Karlin L et al. Monitoring NK cell activity in patients with hematological malignancies. Oncoimmunology 2013; 2: e26011.

19 Lanier LL. NK cell recognition. Annu Rev Immunol 2005; 23: 225-274.

20 Long EO. Negative signaling by inhibitory receptors: the NK cell paradigm. Immunol Rev 2008; 224: 70-84.

21 Bix M, Liao NS, Zijlstra M, Loring J, Jaenisch R, Raulet D. Rejection of class I MHC-deficient haemopoietic cells by irradiated MHCmatched mice. Nature 1991; 349: 329-331.

22 Raulet DH, Guerra N. Oncogenic stress sensed by the immune system: role of natural killer cell receptors. Nat Rev Immunol 2009; 9: 568-580.

23 Nausch N, Cerwenka A. NKG2D ligands in tumor immunity. Oncogene 2008; 27: 5944-5958.

24 Bryceson YT, Ljunggren HG, Long EO. Minimal requirement for induction of natural cytotoxicity and intersection of activation signals by inhibitory receptors. Blood 2009; 114: 2657-2666.

25 Kim HS, Das A, Gross CC, Bryceson YT, Long EO. Synergistic signals for natural cytotoxicity are required to overcome inhibition by $\mathrm{c}-\mathrm{Cbl}$ ubiquitin ligase. Immunity 2010; 32: 175-186.

26 Bryceson YT, March ME, Ljunggren HG, Long EO. Synergy among receptors on resting $\mathrm{NK}$ cells for the activation of natural cytotoxicity and cytokine secretion. Blood 2006; 107: 159-166.

27 Billadeau DD, Upshaw JL, Schoon RA, Dick CJ, Leibson PJ. NKG2DDAP10 triggers human NK cell-mediated killing via a Syk-independent regulatory pathway. Nat Immunol 2003; 4: 557-564.

28 Cooper MA, Elliott JM, Keyel PA, Yang L, Carrero JA, Yokoyama WM. Cytokine-induced memory-like natural killer cells. Proc Natl Acad Sci USA 2009; 106: 1915-1919.

29 Romee R, Schneider SE, Leong JW, Chase JM, Keppel CR, Sullivan RP et al. Cytokine activation induces human memory-like NK cells. Blood 2012; 120: 4751-4760.

30 Lanier LL. Up on the tightrope: natural killer cell activation and inhibition. Nat Immunol 2008; 9: 495-502.

31 Vivier E, Nunes JA, Vely F. Natural killer cell signaling pathways. Science 2004; 306: 1517-1519.

32 Tassi I, Klesney-Tait J, Colonna M. Dissecting natural killer cell activation pathways through analysis of genetic mutations in human and mouse. Immunol Rev 2006; 214: 92-105.

33 Upshaw JL, Arneson LN, Schoon RA, Dick CJ, Billadeau DD, Leibson PJ. NKG2D-mediated signaling requires a DAP10-bound Grb2-Vav1 intermediate and phosphatidylinositol-3-kinase in human natural killer cells. Nat Immunol 2006; 7: 524-532.

34 Bloch-Queyrat C, Fondaneche MC, Chen R, Yin L, Relouzat F, Veillette A et al. Regulation of natural cytotoxicity by the adaptor SAP and the Src-related kinase Fyn. J Exp Med 2005; 202: 181-192.

35 Dong Z, Davidson D, Perez-Quintero LA, Kurosaki T, Swat W, Veillette A. The adaptor SAP controls NK cell activation by regulating the enzymes Vav-1 and SHIP-1 and by enhancing conjugates with target cells. Immunity 2012; 36: 974-985.

36 Eissmann P, Beauchamp L, Wooters J, Tilton JC, Long EO, Watzl C. Molecular basis for positive and negative signaling by the natural killer cell receptor 2B4 (CD244). Blood 2005; 105: 4722-4729.

37 Parolini S, Bottino C, Falco M, Augugliaro R, Giliani S, Franceschini R et al. X-linked lymphoproliferative disease. 2B4 molecules displaying inhibitory rather than activating function are responsible for the inability of natural killer cells to kill Epstein-Barr virus-infected cells. J Exp Med 2000; 192: 337-346.

38 Lee KM, McNerney ME, Stepp SE, Mathew PA, Schatzle JD, Bennett M et al. 2B4 acts as a non-major histocompatibility complex binding inhibitory receptor on mouse natural killer cells. J Exp Med 2004; 199: 1245-1254.

39 Zhang Z, Wu N, Lu Y, Davidson D, Colonna M, Veillette A. DNAM-1 controls NK cell activation via an ITT-like motif. J Exp Med 2015; 212: 2165-2182.

40 Kim HS, Long EO. Complementary phosphorylation sites in the adaptor protein SLP-76 promote synergistic activation of natural killer cells. Sci Signal 2012; 5: ra49.

41 Kwon HJ, Choi GE, Ryu S, Kwon SJ, Kim SC, Booth C et al. Stepwise phosphorylation of p65 promotes NF-kappaB activation and NK cell responses during target cell recognition. Nat Commun 2016; 7: 11686.

42 Kwon HJ, Kwon SJ, Lee H, Park HR, Choi GE, Kang SW et al. NK cell function triggered by multiple activating receptors is negatively 
regulated by glycogen synthase kinase-3beta. Cell Signal 2015; 27: 1731-1741.

43 Cella M, Fujikawa K, Tassi I, Kim S, Latinis K, Nishi S et al. Differential requirements for Vav proteins in DAP10- and ITAM-mediated NK cell cytotoxicity. J Exp Med 2004; 200: 817-823.

44 Tassi I, Presti R, Kim S, Yokoyama WM, Gilfillan S, Colonna M. Phospholipase C-gamma 2 is a critical signaling mediator for murine NK cell activating receptors. J Immunol 2005; 175: 749-754.

45 Caraux A, Kim N, Bell SE, Zompi S, Ranson T, Lesjean-Pottier S et al. Phospholipase C-gamma2 is essential for NK cell cytotoxicity and innate immunity to malignant and virally infected cells. Blood 2006; 107: 994-1002.

46 Upshaw JL, Schoon RA, Dick CJ, Billadeau DD, Leibson PJ. The isoforms of phospholipase C-gamma are differentially used by distinct human NK activating receptors. J Immunol 2005; 175: 213-218.

47 Ombrello MJ, Remmers EF, Sun G, Freeman AF, Datta S, Torabi-Parizi P et al. Cold urticaria, immunodeficiency, and autoimmunity related to PLCG2 deletions. N Engl J Med 2012; 366: 330-338.

48 Schulze-Luehrmann J, Ghosh S. Antigen-receptor signaling to nuclear factor kappa B. Immunity 2006; 25: 701-715.

49 Vallabhapurapu S, Karin M. Regulation and function of NF-kappaB transcription factors in the immune system. Ann Rev Immunol 2009; 27: 693-733.

50 Orange JS, Brodeur SR, Jain A, Bonilla FA, Schneider LC, Kretschmer R et al. Deficient natural killer cell cytotoxicity in patients with IKK-gamma/ NEMO mutations. J Clin Invest 2002; 109: 1501-1509.

51 Pannicke U, Baumann B, Fuchs S, Henneke P, Rensing-Ehl A, Rizzi M et al. Deficiency of innate and acquired immunity caused by an IKBKB mutation. N Engl J Med 2013; 369: 2504-2514.

52 Gross O, Grupp C, Steinberg C, Zimmermann S, Strasser D, Hannesschlager $\mathrm{N}$ et al. Multiple ITAM-coupled NK-cell receptors engage the Bcl10/Malt1 complex via Carmal for NF-kappaB and MAPK activation to selectively control cytokine production. Blood 2008; 112: 2421-2428.

53 Pandey R, DeStephan CM, Madge LA, May MJ, Orange JS. NKp30 ligation induces rapid activation of the canonical NF-kappaB pathway in NK cells. J Immunol 2007; 179: 7385-7396.

54 Duan L, Reddi AL, Ghosh A, Dimri M, Band H. The Cbl family and other ubiquitin ligases: destructive forces in control of antigen receptor signaling. Immunity 2004; 21: 7-17.

55 Huang F, Gu H. Negative regulation of lymphocyte development and function by the Cbl family of proteins. Immunol Rev 2008; 224: 229-238.

56 Liu YC. Ubiquitin ligases and the immune response. Annu Rev Immunol 2004; 22: 81-127.

57 Thien CB, Langdon WY. c-Cbl and Cbl-b ubiquitin ligases: substrate diversity and the negative regulation of signalling responses. Biochem J 2005; 391(Pt 2): 153-166.

58 Naramura M, Kole HK, Hu RJ, Gu H. Altered thymic positive selection and intracellular signals in Cbl-deficient mice. Proc Natl Acad Sci USA 1998; 95: 15547-15552.

59 Wang HY, Altman Y, Fang D, Elly C, Dai Y, Shao Y et al. Cbl promotes ubiquitination of the $\mathrm{T}$ cell receptor zeta through an adaptor function of Zap-70. J Biol Chem 2001; 276: 26004-26011.

60 Miura-Shimura Y, Duan L, Rao NL, Reddi AL, Shimura H, Rottapel R et al. $\mathrm{Cbl}$-mediated ubiquitinylation and negative regulation of Vav. J Biol Chem 2003; 278: 38495-38504.

61 Balagopalan L, Barr VA, Sommers CL, Barda-Saad M, Goyal A, Isakowitz MS et al. c-Cbl-mediated regulation of LAT-nucleated signaling complexes. Mol Cell Biol 2007; 27: 8622-8636.

62 Naramura M, Jang IK, Kole H, Huang F, Haines D, Gu H. c-Cbl and CbI-b regulate $T$ cell responsiveness by promoting ligand-induced TCR downmodulation. Nat Immunol 2002; 3: 1192-1199.

63 Fang D, Wang HY, Fang N, Altman Y, Elly C, Liu YC. Cbl-b, a RING-type E3 ubiquitin ligase, targets phosphatidylinositol 3-kinase for ubiquitination in T cells. J Biol Chem 2001; 276: 4872-4878.

64 Paolino M, Choidas A, Wallner S, Pranjic B, Uribesalgo I, Loeser S et al. The E3 ligase Cbl-b and TAM receptors regulate cancer metastasis via natural killer cells. Nature 2014; 507: 508-512.

65 Beurel E, Michalek SM, Jope RS. Innate and adaptive immune responses regulated by glycogen synthase kinase-3 (GSK3). Trends Immunol 2010; 31: 24-31.

66 Jope RS, Johnson GV. The glamour and gloom of glycogen synthase kinase-3. Trends Biochem Sci 2004; 29: 95-102.
67 Parameswaran R, Ramakrishnan P, Moreton SA, Xia Z, Hou Y, Lee DA et al. Repression of GSK3 restores NK cell cytotoxicity in AML patients. Nat Commun 2016; 7: 11154.

68 Yang E, Singh BK, Paustian AM, Kambayashi T. Diacylglycerol kinase zeta is a target to enhance NK cell function. J Immunol 2016; 197: 934-941.

69 Liu CH, Machado FS, Guo R, Nichols KE, Burks AW, Aliberti JC et al. Diacylglycerol kinase zeta regulates microbial recognition and host resistance to Toxoplasma gondii. J Exp Med 2007; 204: 781-792.

70 Joshi RP, Schmidt AM, Das J, Pytel D, Riese MJ, Lester M et al. The zeta isoform of diacylglycerol kinase plays a predominant role in regulatory $T$ cell development and TCR-mediated ras signaling. Sci Signal 2013; 6: ra102.

71 Schmidt AM, Zou T, Joshi RP, Leichner TM, Pimentel MA, Sommers CL et al. Diacylglycerol kinase zeta limits the generation of natural regulatory T cells. Sci Signal 2013; 6: ra101.

72 Delconte RB, Kolesnik TB, Dagley LF, Rautela J, Shi W, Putz EM et al. $\mathrm{CIS}$ is a potent checkpoint in NK cell-mediated tumor immunity. Nat Immunol 2016; 17: 816-824.

73 Palmer DC, Guittard GC, Franco Z, Crompton JG, Eil RL, Patel SJ et al. Cish actively silences TCR signaling in CD8 $+\mathrm{T}$ cells to maintain tumor tolerance. J Exp Med 2015; 212: 2095-2113.

74 Tassi I, Cella M, Gilfillan S, Turnbull I, Diacovo TG, Penninger JM et al. p110gamma and p110delta phosphoinositide 3-kinase signaling pathways synergize to control development and functions of murine NK cells. Immunity 2007; 27: 214-227.

75 Kim N, Saudemont A, Webb L, Camps M, Ruckle T, Hirsch E et al. The p110delta catalytic isoform of PI3K is a key player in NK-cell development and cytokine secretion. Blood 2007; 110: 3202-3208.

76 Saudemont A, Garcon F, Yadi H, Roche-Molina M, Kim N, SegondsPichon $A$ et al. p110gamma and p110delta isoforms of phosphoinositide 3-kinase differentially regulate natural killer cell migration in health and disease. Proc Natl Acad Sci USA 2009; 106: 5795-5800.

77 De Henau O, Rausch M, Winkler D, Campesato LF, Liu C, Cymerman DH et al. Overcoming resistance to checkpoint blockade therapy by targeting PI3Kgamma in myeloid cells. Nature 2016; 539: 443-447.

78 Kaneda MM, Messer KS, Ralainirina N, Li H, Leem CJ, Gorjestani S et al. $\mathrm{PI} 3 \mathrm{Kgamma}$ is a molecular switch that controls immune suppression. Nature 2016; 539: 437-442.

79 Rosenberg SA, Lotze MT, Muul LM, Leitman S, Chang AE, Ettinghausen $\mathrm{SE}$ et al. Observations on the systemic administration of autologous lymphokine-activated killer cells and recombinant interleukin-2 to patients with metastatic cancer. N Engl J Med 1985; 313: 1485-1492.

80 West WH, Tauer KW, Yannelli JR, Marshall GD, Orr DW, Thurman GB et al. Constant-infusion recombinant interleukin-2 in adoptive immunotherapy of advanced cancer. N Engl J Med 1987; 316: 898-905.

81 Ito S, Bollard CM, Carlsten M, Melenhorst JJ, Biancotto A, Wang E et al. Ultra-low dose interleukin-2 promotes immune-modulating function of regulatory T cells and natural killer cells in healthy volunteers. Mol Ther 2014; 22: 1388-1395.

82 Kennedy-Nasser AA, Ku S, Castillo-Caro P, Hazrat Y, Wu MF, Liu H et al. Ultra low-dose IL-2 for GVHD prophylaxis after allogeneic hematopoietic stem cell transplantation mediates expansion of regulatory $T$ cells without diminishing antiviral and antileukemic activity. Clin Cancer Res 2014; 20: 2215-2225.

83 Sim GC, Liu C, Wang E, Liu H, Creasy C, Dai Z et al. IL2 variant circumvents ICOS+ regulatory T-cell expansion and promotes NK cell activation. Cancer Immunol Res 2016; 4: 983-994.

84 Ghasemi R, Lazear E, Wang X, Arefanian S, Zheleznyak A, Carreno BM et al. Selective targeting of IL-2 to NKG2D bearing cells for improved immunotherapy. Nat Commun 2016; 7: 12878.

85 Bell CJ, Sun Y, Nowak UM, Clark J, Howlett S, Pekalski ML et al. Sustained in vivo signaling by long-lived IL-2 induces prolonged increases of regulatory T cells. J Autoimmun 2015; 56: 66-80.

86 Koka R, Burkett P, Chien M, Chai S, Boone DL, Ma A. Cutting edge: murine dendritic cells require IL-15R alpha to prime NK cells. J Immunol 2004; 173: 3594-3598.

87 Dubois S, Patel HJ, Zhang M, Waldmann TA, Muller JR. Preassociation of IL-15 with IL-15R alpha-IgG1-Fc enhances its activity on proliferation of NK and CD8+/CD44 high T cells and its antitumor action. J Immunol 2008; 180: 2099-2106. 
88 Wu Z, Xu Y. IL-15R alpha-lgG1-Fc enhances IL-2 and IL-15 anti-tumor action through NK and CD8+ T cells proliferation and activation. $J \mathrm{Mol}$ Cell Biol 2010; 2: 217-222.

89 Guo Y, Luan L, Rabacal W, Bohannon JK, Fensterheim BA, Hernandez A et al. IL-15 superagonist-mediated immunotoxicity: role of NK cells and IFN-gamma. J Immunol 2015; 195: 2353-2364.

$90 \mathrm{Kim}$ PS, Kwilas AR, Xu W, Alter S, Jeng EK, Wong HC et al. IL-15 superagonist/IL-15RalphaSushi-Fc fusion complex (IL-15SA/IL-15RalphaSu-Fc; ALT-803) markedly enhances specific subpopulations of NK and memory CD8+ T cells, and mediates potent anti-tumor activity against murine breast and colon carcinomas. Oncotarget 2016; 7: 16130-16145.

91 Allavena P, Paganin C, Zhou D, Bianchi G, Sozzani S, Mantovani A. Interleukin-12 is chemotactic for natural killer cells and stimulates their interaction with vascular endothelium. Blood 1994; 84: 2261-2268.

92 Lauwerys BR, Renauld JC, Houssiau FA. Synergistic proliferation and activation of natural killer cells by interleukin 12 and interleukin 18 . Cytokine 1999; 11: 822-830.

93 Lasek W, Zagozdzon R, Jakobisiak M. Interleukin 12: still a promising candidate for tumor immunotherapy? Cancer Immunol Immunother 2014; 63: 419-435.

94 Leong JW, Chase JM, Romee R, Schneider SE, Sullivan RP, Cooper MA et al. Preactivation with IL-12, IL-15, and IL-18 induces CD25 and a functional high-affinity IL-2 receptor on human cytokine-induced memory-like natural killer cells. Biol Blood Marrow Transplant 2014; 20: 463-473.

95 Shah NN, Baird K, Delbrook CP, Fleisher TA, Kohler ME, Rampertaap S et al. Acute GVHD in patients receiving IL-15/4-1BBL activated NK cells following T-cell-depleted stem cell transplantation. Blood 2015; 125: 784-792.

96 Szmania S, Lapteva N, Garg T, Greenway A, Lingo J, Nair B et al. Ex vivoexpanded natural killer cells demonstrate robust proliferation in vivo in high-risk relapsed multiple myeloma patients. J Immunother 2015; 38: 24-36.

97 Callahan MK, Postow MA, Wolchok JD, Targeting T. Cell co-receptors for cancer therapy. Immunity 2016; 44: 1069-1078.

98 Pesce S, Greppi M, Tabellini G, Rampinelli F, Parolini S, Olive D et al. Identification of a subset of human natural killer cells expressing high levels of programmed death 1 : a phenotypic and functional characterization. J Allergy Clin Immunol 2017; 139: 335-346.

99 Della Chiesa M, Pesce S, Muccio L, Carlomagno S, Sivori S, Moretta A et al. Features of memory-like and PD-1(+) human NK cell subsets. Front Immunol 2016; 7: 351.

100 Beldi-Ferchiou A, Lambert M, Dogniaux S, Vely F, Vivier E, Olive D et al. PD-1 mediates functional exhaustion of activated NK cells in patients with Kaposi sarcoma. Oncotarget 2016; 7: 72961-72977.

101 Benson DM Jr, Bakan CE, Mishra A, Hofmeister CC, Efebera Y, Becknell B et al. The PD-1/PD-L1 axis modulates the natural killer cell versus multiple myeloma effect: a therapeutic target for CT-011, a novel monoclonal anti-PD-1 antibody. Blood 2010; 116: 2286-2294.

102 Stojanovic A, Fiegler N, Brunner-Weinzierl M, Cerwenka A. CTLA-4 is expressed by activated mouse NK cells and inhibits NK Cell IFN-gamma production in response to mature dendritic cells. J Immunol 2014; 192: 4184-4191.

103 Luque I, Reyburn H, Strominger JL. Expression of the CD80 and CD86 molecules enhances cytotoxicity by human natural killer cells. Hum Immunol 2000; 61: 721-728.

104 Jie HB, Schuler PJ, Lee SC, Srivastava RM, Argiris A, Ferrone S et al. CTLA-4(+) regulatory $T$ cells increased in cetuximab-treated head and neck cancer patients suppress NK cell cytotoxicity and correlate with poor prognosis. Cancer Res 2015; 75: 2200-2210.

105 Lang S, Vujanovic NL, Wollenberg B, Whiteside TL. Absence of B7.1CD28/CTLA-4-mediated co-stimulation in human NK cells. Eur J Immunol 1998; 28: 780-786.

106 Cook CH, Chen L, Wen J, Zimmerman P, Zhang Y, Trgovcich J et al. CD28/B7-mediated co-stimulation is critical for early control of murine cytomegalovirus infection. Viral Immunol 2009; 22: 91-103.

107 Benson DM Jr, Hofmeister CC, Padmanabhan S, Suvannasankha A, Jagannath $\mathrm{S}$, Abonour $\mathrm{R}$ et al. A phase 1 trial of the anti-KIR antibody IPH2101 in patients with relapsed/refractory multiple myeloma. Blood 2012; 120: 4324-4333.

108 Vey N, Bourhis JH, Boissel N, Bordessoule D, Prebet T, Charbonnier A et al. A phase 1 trial of the anti-inhibitory KIR mAb IPH2101 for AML in complete remission. Blood 2012; 120: 4317-4323.
109 Wang Z, Zhu J, Gu H, Yuan Y, Zhang B, Zhu D et al. The clinical significance of abnormal Tim-3 expression on NK cells from patients with gastric cancer. Immunol Invest 2015; 44: 578-589.

$110 \mathrm{Xu}$ L, Huang Y, Tan L, Yu W, Chen D, Lu C et al. Increased Tim-3 expression in peripheral NK cells predicts a poorer prognosis and Tim-3 blockade improves NK cell-mediated cytotoxicity in human lung adenocarcinoma. Int Immunopharmacol 2015; 29: 635-641.

111 Komita H, Koido S, Hayashi K, Kan S, Ito M, Kamata Y et al. Expression of immune checkpoint molecules of $\mathrm{T}$ cell immunoglobulin and mucin protein 3/galectin-9 for NK cell suppression in human gastrointestinal stromal tumors. Oncol Rep 2015; 34: 2099-2105.

112 Gallois A, Silva I, Osman I, Bhardwaj N. Reversal of natural killer cell exhaustion by TIM-3 blockade. Oncoimmunology 2014; 3: e946365.

113 Folgiero V, Cifaldi L, Li Pira G, Goffredo BM, Vinti L, Locatelli F. TIM-3/ Gal-9 interaction induces IFNgamma-dependent IDO1 expression in acute myeloid leukemia blast cells. J Hematol Oncol 2015; 8: 36.

114 Blake SJ, Dougall WC, Miles JJ, Teng MW, Smyth MJ. Molecular pathways: targeting CD96 and TIGIT for cancer immunotherapy. Clin Cancer Res 2016; 22: 5183-5188.

115 Johnston RJ, Comps-Agrar L, Hackney J, Yu X, Huseni M, Yang Y et al. The immunoreceptor TIGIT regulates antitumor and antiviral CD8(+) T cell effector function. Cancer Cell 2014; 26: 923-937.

116 Glienke W, Esser R, Priesner C, Suerth JD, Schambach A, Wels WS et al. Advantages and applications of CAR-expressing natural killer cells. Front Pharmacol 2015; 6: 21.

117 Karpovsky B, Titus JA, Stephany DA, Segal DM. Production of targetspecific effector cells using hetero-cross-linked aggregates containing anti-target cell and anti-Fc gamma receptor antibodies. J Exp Med 1984; 160: $1686-1701$

118 Perez P, Hoffman RW, Shaw S, Bluestone JA, Segal DM. Specific targeting of cytotoxic T cells by anti-T3 linked to anti-target cell antibody. Nature 1985; 316: 354-356.

119 Staerz UD, Kanagawa O, Bevan MJ. Hybrid antibodies can target sites for attack by T cells. Nature 1985; 314: 628-631.

120 Chames P, Baty D. Bispecific antibodies for cancer therapy: the light at the end of the tunnel? mAbs 2009; 1: 539-547.

121 Gleason MK, Verneris MR, Todhunter DA, Zhang B, McCullar V, Zhou SX et al. Bispecific and trispecific killer cell engagers directly activate human NK cells through CD16 signaling and induce cytotoxicity and cytokine production. Mol Cancer Ther 2012; 11: 2674-2684.

122 Schmohl JU, Gleason MK, Dougherty PR, Miller JS, Vallera DA. Heterodimeric bispecific single chain variable fragments (scFv) killer engagers (BiKEs) enhance NK-cell activity against CD133+ colorectal cancer cells. Target Oncol 2016; 11: 353-361.

123 Vallera DA, Felices M, McElmurry R, McCullar V, Zhou X, Schmohl JU et al. IL15 trispecific killer engagers (TriKE) make natural killer cells specific to CD33+ targets while also inducing persistence, in vivo expansion, and enhanced function. Clin Cancer Res 2016; 22: 3440-3450.

124 Leong JW, Wagner JA, Ireland AR, Fehniger TA. Transcriptional and posttranscriptional regulation of NK cell development and function. Clin Immunol 2016; S1521-S661630030-4.

$125 \mathrm{Kim}$ TD, Lee SU, Yun S, Sun HN, Lee SH, Kim JW et al. Human microRNA-27a* targets Prf1 and GzmB expression to regulate NK-cell cytotoxicity. Blood 2011; 118: 5476-5486.

126 Kim N, Kim M, Yun S, Doh J, Greenberg PD, Kim TD et al. MicroRNA-150 regulates the cytotoxicity of natural killers by targeting perforin-1. J Allergy Clin Immunol 2014; 134: 195-203.

127 Gong J, Liu R, Zhuang R, Zhang Y, Fang L, Xu Z et al. miR-30c-1* promotes natural killer cell cytotoxicity against human hepatoma cells by targeting the transcription factor HMBOX1. Cancer Sci 2012; 103: 645-652.

128 Jasinski-Bergner S, Reches A, Stoehr C, Massa C, Gonschorek E, Huettelmaier $S$ et al. Identification of novel microRNAs regulating HLA-G expression and investigating their clinical relevance in renal cell carcinoma. Oncotarget 2016; 7: 26866-26878.

129 Bian X, Si Y, Zhang M, Wei R, Yang X, Ren H et al. Down-expression of miR-152 lead to impaired anti-tumor effect of NK via upregulation of HLA-G. Tumour Biol 2016; 37: 3749-3756.

$130 \mathrm{Ni}$ F, Guo C, Sun R, Fu B, Yang Y, Wu L et al. MicroRNA transcriptomes of distinct human NK cell populations identify miR-362-5p as an essential regulator of NK cell function. Sci Rep 2015; 5: 9993. 
131 Ruggeri L, Capanni M, Urbani E, Perruccio K, Shlomchik WD, Tosti A et al. Effectiveness of donor natural killer cell alloreactivity in mismatched hematopoietic transplants. Science 2002; 295: 2097-2100.

132 Domogala A, Madrigal JA, Saudemont A. Natural killer cell immunotherapy: from bench to bedside. Front Immunol 2015; 6: 264.

133 Childs RW, Carlsten M. Therapeutic approaches to enhance natural killer cell cytotoxicity against cancer: the force awakens. Nat Rev Drug Discov 2015; 14: 487-498.

134 Choi I, Yoon SR, Park SY, Kim H, Jung SJ, Jang YJ et al. Donor-derived natural killer cells infused after human leukocyte antigen-haploidentical hematopoietic cell transplantation: a dose-escalation study. Biol Blood Marrow Transplant 2014; 20: 696-704. (c) (i) () $\ominus$ This work is licensed under a Creative Commons Attribution-NonCommercial-NoDerivs 4.0 International License. The images or other third party material in this article are included in the article's Creative Commons license, unless indicated otherwise in the credit line; if the material is not included under the Creative Commons license, users will need to obtain permission from the license holder to reproduce the material. To view a copy of this license, visit http://creativecommons.org/licenses/by-nc-nd/4.0/ 